\title{
O Impacto do Ensino de Regras Morfológicas na Escrita
}

\author{
Viviane do Rocio Barbosa - Universidade Federal do Paraná, Curitiba, Brasil \\ Sandra Regina Kirchner Guimarães - Universidade Federal do Paraná, Curitiba, Brasil \\ João Rosa - Escola Superior de Educação do Instituto Politécnico de Lisboa, Lisboa, Portugal
}

\begin{abstract}
Resumo
Este estudo investiga a contribuição do ensino de regras morfológicas para a escrita de palavras e pseudopalavras. Participaram 111 (cento e onze) alunos do $4^{\circ}$ ano fundamental de uma escola pública, separados em três grupos experimentais e um grupo de controle. Os estudantes foram submetidos a pré-teste e pós-teste (imediato e diferido) em medidas de controle e discriminação escrita. A intervenção trabalhou com o ensino explícito de regras abordando os seguintes elementos mórficos: "-esa"/“-eza" (morfologia derivacional), “-am”/“-ão” (morfologia flexional), “-iu”/“-il”" (morfologia flexional e derivacional). Os resultados mostraram que a intervenção provocou um impacto específico no aumento de desempenho na escrita de palavras e, principalmente, na escrita de pseudopalavras, cuja grafia não pode ser acessada de informações lexicais. Os resultados corroboram os de outros estudos, confirmando o efeito positivo e duradouro do ensino explícito de regras morfológicas sobre a escrita de palavras complexas.

Palavras-chave: Habilidades para escrita, ortografia, morfologia (linguística).
\end{abstract}

The Impact of Teaching Morphological Rules in Writing

\begin{abstract}
This study investigates how teaching morphological rules contributes to the writing of words and pseudo-words. A total of 111 students from the $4^{\text {th }}$ grade of a public school were assigned to three experimental groups and one control group. The students were submitted to pre- and post-tests (immediate and delayed) in control measures and word discrimination. The intervention addressed the explicit teaching of rules concerning the following morphological elements in Portuguese: "-esa"/“-eza" (derivational morphology), “-am"/“-ão" (inflectional morphology), “-iu”/“-il” (inflectional and derivational morphology). The results show that the intervention had a specific impact on improved performance in the spelling of words, especially pseudo-words, the spelling of which cannot be derived from lexical information. The results corroborate those reported by other studies, confirming the positive and lasting effect of explicitly teaching morphological rules for the spelling of complex words. Keywords: Spelling ability, orthography, morphology (linguistics).
\end{abstract}

El Impacto de la Enseñanza de Reglas Morfológicas en la Escritura

\begin{abstract}
Resumen
Este estudio investiga la contribución de la enseñanza de reglas morfológicas para la escritura de palabras y seudopalabras. Participaron 111 (ciento once) alumnos de $4^{\circ}$ año de la enseñanza primaria de una escuela pública, separados en tres grupos experimentales y uno de control. Los estudiantes se sometieron a un pre-test y post-test (inmediato y diferido) en medidas de control y discriminación escrita. La intervención trabajó con la enseñanza explícita de reglas que abordan los siguientes elementos mórficos: “-esa”/“-eza” (morfología derivativa), “-am”/“-ao” (morfología flexiva), "-iu”/“-il” (morfología flexiva y derivativa). Los resultados mostraron que la intervención provocó un impacto específico en el aumento de desempeño en la escritura de palabras y, principalmente, en la escritura de pseudopalabras, cuya ortografía no puede ser accedida por informaciones de léxico. Los resultados corroboran los de otros estudios, confirmando el efecto positivo y duradero de la enseñanza explícita de reglas morfológicas sobre la escritura de palabras complejas.

Palabras clave: Habilidades para la escritura, ortografía, morfología (lingüística).
\end{abstract}

\section{Introdução}

Neste artigo, examina-se o papel que a consciência morfológica desempenha sobre o aperfeiçoamento da linguagem escrita. Essa é uma questão importante porque ainda são poucas - especialmente no Brasil - as pesquisas sobre tal temática.

O conhecimento relativo à morfologia é relevante para a aprendizagem da escrita em línguas alfabéticas porque, nessas línguas, a ortografia é regida por dois

Disponivel em wnw.scielo.br princípios, primordiais para o seu funcionamento (Marec-Breton \& Gombert, 2004). O primeiro princípio, o fonográfico, descreve as correspondências entre unidades gráficas (grafemas) e sons (fonemas). O segundo princípio é o semiográfico e diz respeito às relações entre unidades gráficas e formas significativas. As menores unidades de significação são justamente os morfemas, os quais podem constituir palavras simples (constituídas de um único morfema, por exemplo, o substantivo flor) ou palavras complexas (constituídas de 
dois ou mais morfemas, por exemplo, a palavra florzinha, que é composta pelos morfemas flor e -(z)inha) (Marec-Breton \& Gombert, 2004).

O princípio alfabético refere-se à ideia de que as letras que compõem nossa língua escrita representam os sons individuais das palavras faladas (Byrne, 1998). No Português, isso não acontece sempre biunivocamente (para cada som uma letra), pois existe uma grande variedade relativa ao grau de correspondência entre letras e sons da fala (Faraco, 2012). Conforme Camara Jr. (2007), o critério fonológico rege a nossa escrita, o que se revela já pela tentativa de representação dos fonemas por letras. Entretanto, essa tradução sistemática entre fonemas e grafemas não servirá em todas as situações de escrita, ou seja, usar apenas a estratégia fonológica não dá conta de todas as situações de escrita e, por isso, fazem-se necessários conhecimentos morfológicos, fundamentais para a escrita correta das palavras (Pires, 2010) e, em decorrência, para a obtenção da consciência morfológica.

Assim, consciência morfológica refere-se à habilidade de reflexão e manipulação da estrutura morfológica da língua, ou seja, reflexão a respeito das unidades de sentido (Nunes \& Bryant, 2006; 2009). É por meio dessa habilidade que o sujeito poderá reconhecer e entender as palavras escritas ou as partes que constituem palavras complexas, como, por exemplo, em livro, livrinho, livreiro, livraria, em que a raiz livr- é o morfema comum e indica uma significação básica nesse grupo lexical (Rocha, 1998).

Nos sistemas alfabéticos, como é o caso do Português, os morfemas (unidades mínimas de significado) podem ser derivacionais (o sufixo "-eiro" forma substantivos-agentivos a partir de substantivos, por exemplo: pedra/pedreiro) ou flexionais (o sufixo "-s" marca o plural, por exemplo: casa/casas). Além disso, caracterizam-se como blocos de construção nos processos de formação de palavras, "elementos recorrentes, de grande produtividade na língua" e sua ordem é rígida, ou seja, "qualquer alteração resulta em formas inaceitáveis na língua” (Kehdi, 2007, p. 15).

Em relação à natureza da significação, existem dois tipos de morfemas: os lexicais e os gramaticais. Segundo Paula (2007), "o morfema lexical constitui o elemento central de significado da palavra, ao qual podem ser agregados outros morfemas, para qualificar o conceito que este representa" (p. 7). Ele tem significação externa e relaciona-se ao mundo extralinguístico; é também conhecido como lexema ou semantema. (Cunha \& Cintra, 2008). No que se refere às classes de palavras, os morfemas lexicais são "os substantivos, os adjetivos, os verbos e os advérbios de modo" (Cunha \& Cintra, 2008, p. 91). Já os morfemas gramaticais não possuem significação independente, ou seja, a significação nos morfemas gramaticais é interna e "deriva das relações e categorias levadas em conta pela língua" (Cunha \& Cintra, 2008, p. 91). Assim, na frase-exemplo apresentada por Cunha e Cintra (2008, p. 91): "Évora! Ruas ermas sob os céus cor de violetas roxas...", identificam-se "O artigo $o$, as preposições de e sob, a marca de feminino -a (rox-a, erm-a) e a de plural -s (rua-s, erma-s, o-s, céus, violeta-s, roxa-s)." Portanto, pode-se dizer que os morfemas flexionais são os responsáveis pela alteração dos morfemas lexicais, de tal maneira que estes sejam ajustados "à expressão das categorias gramaticais que a sua classe admite", ou seja, nomes devem adequar-se a gênero e número, e verbos, a tempo e modo, número e pessoa (Silva \& Koch, 1997, p. 22). Ademais, é importante salientar que "enquanto nas derivações as palavras podem ter uma extensão no significado, as flexões mantêm uma estabilidade semântica." (Guimarães \& Paula, 2010, p. 96).

Em busca de respostas a inúmeras indagações que se fazem no campo investigativo sobre consciência morfológica, estudos estrangeiros (Arranhado, 2010; Carlisle, 1995, 1996, 2000; Deacon \& Bryant, 2005; Deacon, Kirby, \& Bell-Casselman, 2009; Rosa, 2003; Pires, 2010) e nacionais (Guimarães, 2005, 2011, 2013; Mota, 2007, 2008, 2012; Mota, Anibal, \& Lima 2008; Paula, 2007; Queiroga, Lins, \& Pereira, 2006) têm apresentado evidências empíricas de que as habilidades metamorfológicas podem influenciar tanto na aprendizagem inicial da linguagem escrita quanto no seu desenvolvimento, contribuindo para um maior domínio da leitura e da escrita.

Um dos primeiros estudos que investigou o papel da consciência morfológica na aprendizagem inicial da escrita foi realizado por Carlisle (1995) com crianças falantes do inglês. Nesse estudo, a pesquisadora verificou uma relação significativa entre a consciência morfológica e a aquisição de habilidades em leitura. Em outro estudo, Carlisle (2000) investigou a capacidade de as crianças de $3^{a}$ a $5^{a}$ série reconhecerem a estrutura e o significado das palavras derivadas, concluindo que a habilidade de realizar análises morfológicas está significativamente relacionada à compreensão da leitura.

Além de investigar as relações entre a consciência morfológica e o desenvolvimento da capacidade de leitura, várias pesquisas trataram também da relação entre as habilidades metamorfológicas e o desempenho 
em escrita. Entre elas, o estudo de Carlisle (1996), que investigou o emprego de palavras morfologicamente complexas por crianças de $2^{a}$ e $3^{a}$ série, verificou que os alunos com maior nível de escolaridade (com e sem problemas de aprendizagem) foram mais precisos na utilização de flexões, derivações e palavras compostas. Deacon e Bryant (2005) também examinaram os efeitos do conhecimento de sufixos sobre a escrita de crianças. Seus resultados apontam que as crianças de 5 a 8 anos demonstraram ter consciência das flexões, mas não das derivações. Os autores concluíram que é mais difícil para as crianças entender as relações morfêmicas nas derivações do que nas flexões, em função de que, na morfologia derivacional, há uma mudança na classe gramatical das palavras morfologicamente complexas, o que não ocorre na morfologia flexional. Ainda, em língua inglesa, destaca-se o estudo longitudinal realizado por Deacon, Kirby e Bell-Casselman (2009), que observou como diferentes habilidades cognitivas avaliadas em crianças de 7 anos de idade influenciam seu desempenho na escrita de palavras isoladas dois anos mais tarde. Os resultados apresentados mostram que a consciência morfológica é uma variável importante na determinação do desempenho futuro em escrita geral e que a contribuição da consciência morfológica é independente da contribuição das outras variáveis avaliadas.

Em Portugal, Rosa (2003) desenvolveu estudos, de caráter transversal e longitudinal, os quais foram fundamentais para os que foram desenvolvidos posteriormente pelos pesquisadores do seu laboratório de pesquisa. O objetivo do trabalho de Rosa (2003) consistiu em analisar a relação entre a consciência morfológica e a escrita no Português (variante europeia). Para tanto, foram estudadas duas situações em que a ortografia era determinada pela morfologia: a primeira, quando não se respeitam regras de correspondência letra-som, e a segunda, quando há mais de uma ortografia para o mesmo som, ou seja, existe diferença na escrita de sufixos homófonos. Este estudo apresentou evidências de que a consciência morfológica é uma habilidade que melhora significativamente conforme avança o grau de escolaridade dos alunos. Além disso, mostrou que essa habilidade desempenha um papel específico e significativo na discriminação escrita de palavras que requerem considerações morfológicas.

Entre suas conclusões Rosa (2003) aponta a necessidade de investigações de caráter interventivo, que possam comparar as aprendizagens da escrita como resultado de instruções explícitas e diretas de regras morfológicas com as aprendizagens oriundas de diferentes práticas educativas (tradicionais ou não). Uma série de investigações tem sido realizada para cumprir essa agenda de pesquisa. Um desses estudos foi desenvolvido por Pires (2010), que teve como objetivo avaliar o impacto do ensino explícito das regras morfológicas relativas aos morfemas homófonos "-esa"/ "-eza" e "-ice"/"-isse" na capacidade de os participantes de $3^{\circ}, 4^{\circ}$ e $6^{\circ}$ ano escreverem palavras que terminam com essas formas homófonas. Os resultados mostraram uma contribuição significativa da intervenção sobre a capacidade de escrita dos alunos, ou seja, os participantes que receberam um ensino explícito sobre os princípios morfológicos puderam discriminar, na escrita, morfemas homófonos de forma significativamente melhor do que aqueles que não foram ensinados.

Também integrante do grupo de trabalho coordenado por Rosa, Arranhado (2010) encabeçou uma investigação de caráter interventivo cujo objetivo foi avaliar o impacto da explicitação de regras morfológicas ou fonológicas na correção da escrita de palavras que terminam com os morfemas ("-am"/“-ão"). A discriminação escrita das palavras que terminam nesses morfemas pode ser obtida quer por uma regra fonológica associada à consciência da tônica, quer por uma regra morfológica associada à diferença na escrita de tempos verbais ou à oposição entre tempos verbais e o morfema aumentativo "-ão", conforme descrito inicialmente por Nunes (1992). A intervenção foi desenvolvida com estudantes de $3^{\circ}$ e $4^{\circ}$ ano $(n=90)$ do ensino básico, divididos em três condições experimentais: ensino da regra fonológica, ensino da regra morfológica e controle. Os resultados obtidos neste estudo evidenciam que o ensino explícito de regras, quer fonológicas, quer morfológicas, tem um impacto significativo e equivalente na discriminação das palavras que terminam nos morfemas "-am"/“-ão".

Quanto aos estudos brasileiros sobre consciência morfológica revisados, todos são de caráter correlacional e apontam que as habilidades metamorfológicas apresentam relações significativas estatisticamente tanto com o desempenho em leitura (Guimarães, 2005, 2011; Mota et al., 2008; Paula, 2007) como com o desempenho ortográfico (Guimarães, 2005, 2011, 2013; Mota et al., 2008; Paula, 2007; Queiroga et al., 2006).

Assim, dado o caráter correlacional das investigações brasileiras que reconhecem o poder preditivo da consciência morfológica sob a capacidade de leitura e escrita, o presente estudo teve como objetivo realizar uma intervenção que pudesse promover o desenvolvimento da consciência morfológica e avaliar 
o impacto desses conhecimentos sobre o aperfeiçoamento da escrita.

\section{Método}

\section{Participantes}

O estudo foi realizado com 111 (cento e onze) crianças, de quatro turmas do $4^{\circ}$ ano do Ensino Fundamental, de uma escola da rede pública de ensino. Optou-se por desenvolver este estudo em escolas públicas, pois elas espelham melhor a realidade social do país e isso contribui para a reflexão acerca da importância da morfologia (flexional e derivacional) como conteúdo programático nos anos iniciais do ensino fundamental. $\mathrm{O}$ único critério de inclusão dos alunos como participantes foi a assinatura do Termo de Consentimento Livre e Esclarecido (TCLE) pelos pais ou responsáveis.

\section{Instrumentos}

Tarefa de Escrita, composta por noventa e seis estímulos (48 palavras e 48 pseudopalavras), em contexto de frases, sendo oito para cada tipo de elemento mórfico (-esa; -eza; -am; -ão; -iu; -il) a ser trabalhado na intervenção. Essa prova tinha por objetivo aferir o conhecimento ortográfico das crianças. As palavras aqui utilizadas foram extraídas do acervo de Pinheiro (1996) e o critério de escolha delas foi o grau de sua frequência, ou seja, optou-se por escolher palavras que apareceram nesse corpus em baixa frequência na $3^{\text {a }}$ série, pois é o mesmo grau de escolaridade dos participantes deste estudo. Além disso, a baixa frequência pode favorecer um controle mais rigoroso do conhecimento lexical anterior dos participantes. Já as pseudopalavras foram criadas seguindo o critério de quantidade mínima (cinco), como em zonil e máxima (onze) de letras, como foi o caso de melandearão, visto que, nas palavras, essas quantidades variaram entre quatro - útil - e doze letras - acompanharão. Além disso, evitou-se finalizar as pseudopalavras com sílabas (as duas últimas) que pudessem formar palavras reais. O ditado das frases foi dado a partir das seguintes instruções:

"Vocês irão me ajudar a compreender como uma criança entende como são escritas determinadas palavras. Para isso, eu trouxe algumas palavras reais e outras que en inventei para que vocês as escrevam no contexto de frases. Vou ditá-las para vocês e, para isso, preciso que ouçam as palavras e depois as frases e as registrem na folha que thes dei. Digo a palavra uma vez, depois a frase completa e no final repito a palavra. Se houver dúvidas, peço que não façam nenbum comentário e nem me perguntem nada, pois eu não poderei ajudá-los agora. Registrem como acreditam que esteja certo e depois me entreguem a folba."

Subteste de Vocabulário WISC III, aplicado individualmente, de modo a avaliar o conhecimento lexical dos participantes antes da intervenção.

Prova de Aritmética (Seabra, Montiel, \& Capovilla, 2009), teve como objetivo avaliar a escrita algébrica de números ouvidos, a escrita de sequências numéricas crescente e decrescente, além das quatro operações isoladas ou em situações-problema. Destaca-se que essa prova foi utilizada para medir a especificidade da intervenção.

Consciência de Fonemas - CONFIAS (Moojen et al., 2007), aplicado individualmente, o CONFIAS é um instrumento utilizado na avaliação da consciência fonológica de forma abrangente e sequencial. Para essa investigação, foram utilizados apenas os subtestes do nível de fonema: produção de palavra que inicia com um dado som; identificação de fonema inicial; identificação de fonema final; exclusão; síntese; segmentação; transposição. Os dados obtidos nessa avaliação foram utilizados para o controle da consciência fonológica dos participantes.

Prova de Analogias Gramaticais (Guimarães, 2005), avalia a capacidade de identificação da transformação morfológica apresentada em um par de palavras e a realização de uma transformação similar na primeira palavra de outro par, ou seja, o esquema utilizado é "A" (bondade) está para "B" (bom) assim como "C" (ruindade) está para "D" (ruim). Constitui-se por nove itens (dois de treino e sete de exame), e a eleição dos itens ("B" e "D") foi feita por meio de uma seleção de palavras que não rimam, a fim de evitar uma possível interferência fonológica na execução do exame.

Prova de Derivação e Decomposição em Contexto (Guimarães, 2011, comunicação pessoal), num total de 32 itens, essa prova possui dois tipos de avaliações: a primeira requer do aluno a habilidade de decompor uma palavra derivada pela subtração de seu sufixo, gerando sua forma primitiva, como foi solicitado no exemplo que segue abaixo:

(horroroso) - Aquele filme foi um (horror)

A segunda avaliação exige a ação reversa, pois nesta o examinando deve produzir uma palavra derivada, dada sua forma primitiva:

(jornal) - Preciso aguardar o (jornaleiro) 
Prova de Flexão em Contexto (Guimarães, 2012, comunicação pessoal), composta por 13 (treze) estímulos, os quais envolvem a flexão de substantivos, de adjetivos e verbos. A prova tem como objetivo verificar se o examinado consegue, no contexto de frases, realizar corretamente a flexão das palavras dadas:

(participar) - Ontem teve uma gincana no parque e todas as crianças

\section{Procedimento}

O projeto foi aprovado pelo Comitê de Ética em Pesquisa (CEP/SD 1280.205.11.12, CAAE 0196.0.091.000-11) a partir do que foi conduzida a investigação delineada em quatro fases: pré-teste, intervenção, pós-teste imediato e pós-teste diferido.

Inicialmente, nos pré-testes, os alunos foram avaliados coletivamente na tarefa de escrita (na própria sala de aula). Em seguida, houve duas sessões para a aplicação das outras provas, que foram realizadas de forma escrita, em grupos de, no máximo, 10 (dez) alunos. $\mathrm{Na}$ primeira sessão, aplicaram-se o subteste de vocabulário WISC III e a Prova de Aritmética. Na segunda sessão, foram realizadas as provas de Consciência Morfológica: Prova de Derivação e Decomposição em Contexto, Prova de Flexão em Contexto e Prova de Analogias Gramaticais.

Após os pré-testes, os participantes foram distribuídos, de acordo com seu desempenho nas provas utilizadas como variáveis de controle, em quatro grupos experimentais, um deles caracterizado como controle. Essa distribuição foi obtida por meio de teste estatístico (que será apresentado junto com os resultados), que possibilitou a formação dos grupos com características de desempenho semelhantes, pois se pretendia que os grupos não fossem diferentes no início da intervenção, a qual ocorreu por intermédio de uma das pesquisadoras. O período de intervenção foi realizado com os estudantes agrupados por turno, ou seja, uniram-se os participantes de cada grupo experimental do turno da manhã (turmas A e B) e da tarde (turmas C e D). Assim, a intervenção se deu com grupos que continham as seguintes quantidades de participantes: G1 (manhã) = $14, \mathrm{G} 1(\operatorname{tarde})=13 ; \mathrm{G} 2(\operatorname{manh} \tilde{a})=14, \mathrm{G} 2(\operatorname{tarde})=14$; G3 $($ manhã $)=14, G 3($ tarde $)=14 ; G 4($ manhã $)=14$, $\mathrm{G} 4$ (tarde) $=14$. A ação de instrução/treinamento com os diferentes grupos foi desenvolvida em uma sala de aula oferecida pela escola para tal trabalho, conforme se apresenta a seguir:

Grupo experimental 1: foram feitas cinco sessões de intervenção, de 30 minutos cada, focando o trabalho nas habilidades relativas à morfologia derivacional. Trabalharam-se atividades que explicitavam saberes referentes aos elementos mórficos homófonos "-esa" e "-eza".

Grupo experimental 2: o plano de intervenção (cinco sessões, de 30 minutos cada) enfatizou o trabalho com a regras morfológicas flexionais, a partir da reflexão sobre os elementos mórficos “-am” (em verbos que estejam conjugados no pretérito perfeito, na terceira pessoa do plural) e "-ão" (em verbos que estejam conjugados no futuro do presente, na terceira pessoa do plural).

Grupo experimental 3: recebeu cinco sessões de intervenção (30 minutos cada), as quais foram planejadas em função do trabalho que enfatizou conteúdos de morfologia derivacional e flexional. A intervenção realizada abordou os elementos mórficos homófonos "-il" (em adjetivos) e "-iu (nos casos de grafia de verbos da terceira conjugação “-ir", conjugados no passado, da terceira pessoa do singular).

Grupo controle ativo 4: por motivos éticos, optou-se em beneficiar o grupo controle com algum aprendizado durante o estudo, de modo que esses participantes não se tornem "perdedores na pesquisa" (Nunes \& Bryant, 2006, p. 94) e recebam instrução de um conteúdo distinto dos demais grupos experimentais. Para tanto, a esse grupo de alunos foram ofertadas cinco sessões, de 30 minutos cada, de ensino de conteúdos referentes à matemática, especificamente, o entendimento inicial sobre representação fracionária.

Após a intervenção, fez-se o primeiro pós-teste (as mesmas provas do pré-teste), de modo a verificar o efeito imediato do programa de intervenção sobre o desempenho ortográfico dos participantes e identificar se houve diferença no desempenho ortográfico deles após a participação no programa de intervenção. Além disso, também foi aplicado um pós-teste diferido após um mês da intervenção (parte desse período coincidiu com o recesso escolar de julho), com vistas a verificar se houve um aprendizado consolidado e não apenas imediato.

\section{Resultados}

\section{Vocabulário e Consciência Fonêmica}

Para analisar as diferenças entre os grupos, realizaram-se Análises de Variância (ANOVA) Unifatoriais para todas as variáveis. Em relação ao conhecimento lexical, a ANOVA realizada indicou que os grupos não apresentaram diferenças significativas em nenhum 
momento de testes: pré-teste $(F=0,6 ; g l=3 ; p=0,614)$, pós-teste imediato $(F=1,06 ; g l=3 ; p=0,370)$ e pós-teste diferido $(F=0,15 ; g l=3 ; p=0,927)$. O controle da variável conhecimento lexical foi pertinente e permitiu isolar os saberes trabalhados e aprendidos pelos participantes, sem que o fator vocabulário interferisse nos resultados.

No que se refere à segunda variável de controle - nível de consciência fonêmica, buscou-se também por meio das ANOVAs verificar se as diferenças de desempenho entre os grupos eram significativas estatisticamente em alguns dos momentos avaliados. Os resultados das análises realizadas mostraram que os grupos não apresentaram diferenças significativas em nível de consciência fonêmica no pré-teste $(F=0,13$; $g l=3 ; p=0,943)$, nem nos dois pós-testes - imediato $(F=0,13 ; g l=3 ; p=0,943)$ e diferido $(F=0,128 ; g l=$ $3 ; p=0,943)$. Assim, pode-se afirmar que, como não havia diferenças entre os grupos no pré-teste, quaisquer diferenças encontradas entre os grupos em outras provas não poderão ser atribuídas à consciência fonêmica. Além disso, verificou-se que os grupos continuaram a não ter diferenças significativas entre si nos dois pós-testes de consciência fonêmica. Isso mostra que os aprendizados desenvolvidos na intervenção não foram generalizados em termos de habilidades fonêmicas.

\section{Consciência Morfológica}

A partir da comparação das médias feita por meio da ANOVA, observou-se que, na Prova de Analogias Gramaticais, não houve diferenças significativas estatisticamente em função dos grupos, tanto no pré-teste ( $F$ $=1,20 ; g l=3 ; p=0,312)$ quanto nos pós-testes - imediato $(F=0,95 ; g l=3 ; p=0,419)$ e diferido $(F=0,91$; $g l=3 ; p=0,438)$. O mesmo se constatou nas Provas de Derivação e Decomposição em Contexto - pré-teste $(F=1,3 ; g l=3 ; p=0,268)$; pós-testes - imediato $(F=$ $0,48 ; g l=3 ; p=0,986)$ e diferido $(F=0,55 ; g l=3 ; p=$ $0,650)$ e de Flexão em Contexto - pré-teste $(F=1,00 ; g l$ $=3 ; p=0,398)$; pós-testes - imediato $(F=1,16 ; g l=3 ; p$ $=0,330)$ e diferido $(F=0,57 ; g l=3 ; p=0,638)$. Diante disso, nos resultados obtidos nas tarefas de avaliação da consciência morfológica, chama atenção o fato de que não há diferença significativa entre o desempenho dos grupos em relação a essas tarefas, mesmo depois da intervenção. Esse fato sugere, inicialmente, que uma possível aprendizagem morfológica possibilitada pela intervenção é específica, ou seja, não passível de ser generalizada a ponto de resultar em um aumento da habilidade metamorfológica de modo geral.
Destaca-se que os itens dos elementos da morfologia derivacional e flexional trabalhados na intervenção eram diferentes dos que foram medidos nas tarefas (Analogias morfológicas, Derivação e Decomposição em Contexto e Flexão em Contexto), visto que a gama de elementos avaliados era muito maior. Além disso, nessas tarefas avaliativas, foram solicitados apenas itens contemplando os elementos mórficos: “-eza” (dois itens na tarefa de derivação e decomposição em contexto e três itens na tarefa de analogias gramaticais) e "-am" (dois itens na tarefa de flexão em contexto). Entretanto, já nesse momento é importante destacar que foi uma intervenção breve e talvez não suficiente para provocar desenvolvimento dessas habilidades nos participantes. Contudo, na discussão serão examinados os resultados obtidos nos diferentes momentos das testagens de escrita dos elementos trabalhados na intervenção.

\section{Aritmética}

A ANOVA realizada para verificar se havia diferença entre os grupos no que tange ao conhecimento aritmético evidenciou que, desde o pré-teste $(F=0,78$; $g l=3 ; p=0,505)$ até as outras fases de avaliação, ou seja, no pós-teste imediato $(F=1,6 ; g l=3 ; p=0,194)$ e no pós-teste diferido $(F=1,62 ; g l=3 ; p=0,188)$, os grupos se mostraram sem diferenças significativas estatisticamente.

\section{Escrita de Palavras e Psendopalavras}

Para verificar possíveis diferenças no desempenho dos grupos de participantes na escrita de palavras e pseudopalavras com os elementos mórficos "-esa" / "-eza"; “-am" / "-ão" e "-iu" / "-il", nos diferentes momentos da pesquisa, foram realizadas ANOVAs com os dados obtidos. Cabe ressaltar que, esses resultados foram computados utilizando-se a variável discriminação de palavras e de pseudopalavras para cada um dos pares de elementos mórficos testados (-esa/-eza; -am/-ão; -iu/-il). O cálculo da discriminação na escrita dos pares de elementos mórficos foi realizado de acordo com uma fórmula proposta por Guilford (1954), também usada por Rosa (2003). Nessa fórmula [(D = C - (E/p -1)], o valor de discriminação (D) resulta de subtrair do número de respostas certas $(C)$ o número de respostas erradas $(\mathrm{E})$, dividido pelo número de possibilidades de escrita $(p)$ menos 1(-1). Segundo Guilford (1954), com esse processo controla-se o diferente grau de dificuldade que depende do número de possibilidades de escrita e os acertos unicamente devidos ao acaso. Obtém-se, assim, uma distribuição de scores com um 
valor médio de zero (0) quando o número de escritas corretas é igual ao número de escritas incorretas. Porque as crianças escreveram oito palavras (ou pseudopalavras) de cada par mórfico, o valor mais elevado possível será +16 (completa discriminação) e o valor mais baixo será -16 (a escrita dos elementos mórficos está sistematicamente errada). Esses valores ocorrem quando se consideram duas possibilidades de escrita, como foi o caso de "-esa" /"-eza", em que as crianças usam fundamentalmente $[\mathrm{s}]$ ou $[\mathrm{z}]$ para grafar o som medial desses elementos. Já na escrita de outros elementos mórficos homófonos, em Português, o número de possibilidades de escrita pode ser maior, aumentando assim a dificuldade de discriminação. Por exemplo, nas palavras "tolice" e "fugisse" o som medial de "-ice" e "-isse" pode ser grafado por [s], [ss] e [c] e as crianças fazem ainda, frequentemente, violações contextuais e grafam esse som medial com [c]. A aplicar-se aqui a fórmula de Guilford, as possibilidades de escrita seriam três ou quatro consoante o critério seguido pelo investigador.

Para obtenção do valor da discriminação em todos os pares de palavras e pseudopalavras, foi utilizada a referida fórmula, conforme exemplificado, a seguir, para a discriminação das palavras do par "-esa"/"-eza": D.p.“-esa”/“-eza” = (T.a.p.“-esa”+T.a.p.“-eza”) $(16-($ T.a.p."-esa”+ T.a.p.“-eza”))

onde,

D.p."-esa"/"-eza" = Discriminação de palavras "-esa"/“-eza";

T.a.p."-esa” = total de acertos em palavras com "-esa";

T.a.p."-eza" = total de acertos em palavras com “-eza".

Os resultados das análises feitas no pré-teste mostraram que os grupos não eram diferentes na escrita de pseudopalavras $(F(0,31)=3,11, p=0,826)$ e de palavras $(F(0,96)=3,11, p=0,414)$ com os elementos “-esa”/“-eza”. Também não foi encontrada diferença no desempenho dos grupos na escrita de pseudopala$\operatorname{vras}(F(0,27)=3,11, \mathrm{p}=0,845)$ e palavras $(F(0,45)$ $=3,11, p=0,720)$ com os elementos "-am"/“-ão". Tampouco foi encontra diferença na escrita de pseudopalavras $(F(1,01)=3,11, p=0,393)$ e palavras $(F(0,73)$ $=3,11, p=0,533)$ envolvendo os elementos mórficos “-iu"/“-il".

No pós-teste imediato, o desempenho dos grupos em relação à escrita (discriminação) dos elementos mórficos "-esa"/“-eza" foi significativamente diferente tanto em pseudopalavras $(F=11,58 ; g l=3 ; p=$ $0,000)$ quanto em palavras $(F=5,49 ; g l=3 ; p=0,002)$.
Testes post hoc Student-Knewman-Keuls (SNK para $p<$ $0,05)$ mostraram que o grupo experimental 1, o qual foi objeto de uma intervenção específica nessa área, é significativamente mais capaz do que os outros grupos de discriminar a escrita das pseudopalavras usadas na avaliação $(M=7,33)$. Os testes post hoc mostram ainda que os demais grupos (2, 3 e 4$)$ não se distinguem entre si. Considera-se esse resultado bastante importante, tendo em vista que uma diferença significativa na discriminação de pseudopalavras parece refletir exatamente o efeito da intervenção, dado que, ao escrevê-las, as crianças não poderiam se reportar a conhecimentos lexicais prévios.

No que tange à discriminação de palavras, a comparação dos grupos em pares, usando o teste post hoc Student-Knewman-Keuls (SNK para $p<0,05$ ) mostrou que o desempenho do grupo experimental 1 também foi significativamente superior $(M=7,33)$ que o dos demais grupos, os quais não possuem diferenças significativas entre si.

Para verificar se as diferenças entre os grupos permaneceriam de forma duradoura, foram realizados pós-testes diferidos um mês após as intervenções, conforme descrito no método. A análise de variância (ANOVA) evidencia que, tal como no pós-teste imediato, continuam a existir diferenças significativas entre os grupos quer na discriminação de pseudopala$\operatorname{vras}(F=9,03 ; g l=3 ; p=0,000)$, quer de palavras $(F=$ $6,58 ; g l=3 ; p=0,000)$. A comparação dos grupos em pares, feita com o post hoc Student-Knewman-Keuls (SNK para $p<0,05)$, mostra que o desempenho do grupo 1 foi significativamente superior, tanto na discriminação escrita de pseudopalavras $(M=8,00)$ quanto de palavras $(M=7,41)$, quando comparado com o desempenho dos demais grupos, os quais não apresentam diferenças entre si.

Em relação ao desempenho dos grupos na escrita com os elementos mórficos “-am"/“-ão" no pós-teste imediato, constataram-se, por meio da ANOVA, diferenças significativas entre os grupos, tanto na discriminação de pseudopalavras $(F=10,65 ; g l=3 ; p$ $=0,000)$ quanto de palavras $(F=14,77 ; g l=3 ; p=$ $0,000)$. Ao comparar os grupos em pares, por meio do post hoc Student-Knewman-Keuls (SNK para $p<0,05$ ), verificou-se que essa diferença deve-se ao desempenho significativamente superior do grupo experimental 2, que foi objeto desta intervenção específica, quando comparado ao dos demais grupos, na discriminação tanto de pseudopalavras $(M=10,36)$ como de pala$\operatorname{vras}(M=11,07)$. 
Tabela 1

Média, Desvio Padrão e Nivel de Significância na Anova na Discriminação Escrita (Palavras e Pseudopalavras)

\begin{tabular}{|c|c|c|c|c|c|c|c|c|c|c|}
\hline & \multirow{4}{*}{ Variáveis } & \multicolumn{8}{|c|}{ Grupos } & \multirow{4}{*}{$\begin{array}{l}\text { Nível de } \\
\text { significância } \\
\text { ANOVA }\end{array}$} \\
\hline & & \multirow{2}{*}{\multicolumn{2}{|c|}{$\begin{array}{c}\text { Exp. } 1 \\
\text {-esa/-eza } \\
\text { (27 alunos) } \\
\end{array}$}} & \multirow{2}{*}{\multicolumn{2}{|c|}{$\begin{array}{c}\text { Exp. } 2 \\
\text {-am/-ão } \\
\text { (28 alunos) }\end{array}$}} & \multirow{2}{*}{\multicolumn{2}{|c|}{$\begin{array}{c}\text { Exp. } 3 \\
\text {-iu/-il } \\
\text { (28 alunos) } \\
\end{array}$}} & \multirow{2}{*}{\multicolumn{2}{|c|}{$\begin{array}{l}\text { Controle } \\
\text { (28 alunos) }\end{array}$}} & \\
\hline & & & & & & & & & & \\
\hline & & Média & D.P. & Média & D.P. & Média & D.P. & Média & D.P. & \\
\hline \multirow{2}{*}{ Pré-teste } & $\begin{array}{c}\text { palavras } \\
\text {-esa/-eza }\end{array}$ & 2,59 & 4,07 & 1,71 & 4,1 & 1,14 & 2,95 & 1,07 & 3,79 & $p=0,41$ \\
\hline & $\begin{array}{c}\text { pseudopalavras } \\
\text {-esa/-eza }\end{array}$ & 0,15 & 2,82 & 0,36 & 3,27 & $-0,36$ & 2,18 & 0,07 & 2,95 & $p=0,82$ \\
\hline \multirow{2}{*}{$\begin{array}{l}\text { Pós-teste } \\
\text { imediato }\end{array}$} & $\begin{array}{l}\text { palavras } \\
\text {-esa/-eza }\end{array}$ & 7,33 & 7,21 & 3,64 & 4,83 & 2,07 & 5,21 & 2,29 & 4,03 & $p=0,002^{* *}$ \\
\hline & $\begin{array}{c}\text { pseudopalavras } \\
\text {-esa/-eza }\end{array}$ & 7,33 & 9,38 & $-0,14$ & 4,03 & $-1,36$ & 4,29 & 1,07 & 4,5 & $p<0,001^{* *}$ \\
\hline \multirow{2}{*}{$\begin{array}{l}\text { Pós-teste } \\
\text { diferido }\end{array}$} & $\begin{array}{l}\text { palavras } \\
\text {-esa/-eza }\end{array}$ & 7,41 & 5,29 & 2,64 & 5,08 & 2,71 & 4,26 & 2,64 & 4,62 & $p<0,001^{* *}$ \\
\hline & $\begin{array}{c}\text { pseudopalavras } \\
\text {-esa/-eza }\end{array}$ & 8 & 7,15 & 1,29 & 5,84 & 0,21 & 5,51 & 1,29 & 6,23 & $p<0,001^{* *}$ \\
\hline \multirow{2}{*}{ Pré-teste } & $\begin{array}{l}\text { palavras } \\
\text {-am/-ão }\end{array}$ & 2,44 & 5,5 & 2,5 & 6,63 & 1,07 & 3,24 & 1,93 & 4,94 & $p=0,72$ \\
\hline & $\begin{array}{c}\text { pseudopalavras } \\
\text {-am/-ão }\end{array}$ & 3,85 & 5,35 & 3 & 6,47 & 2,57 & 4,03 & 3,07 & 5,23 & $p=0,85$ \\
\hline \multirow{2}{*}{$\begin{array}{l}\text { Pós-teste } \\
\text { imediato }\end{array}$} & $\begin{array}{c}\text { palavras } \\
\text {-am /-ão }\end{array}$ & 2,07 & 5,8 & 11,07 & 5,09 & 2,36 & 6,25 & 3,93 & 5,97 & $p<0,001^{* *}$ \\
\hline & $\begin{array}{l}\text { pseudopalavras } \\
\text {-am/-ão }\end{array}$ & 3,56 & 3,36 & 10,36 & 5,6 & 2,79 & 5,87 & 4,21 & 5,61 & $p<0,001 * *$ \\
\hline \multirow{2}{*}{$\begin{array}{l}\text { Pós-teste } \\
\text { diferido }\end{array}$} & $\begin{array}{l}\text { palavras } \\
\text {-am/-ão }\end{array}$ & 4,3 & 5,73 & 8,79 & 6,63 & 3,57 & 5,72 & 4,21 & 6,4 & $p=0,007^{* *}$ \\
\hline & $\begin{array}{l}\text { pseudopalavras } \\
\text {-am/-ão }\end{array}$ & 5,63 & 6 & 8,79 & 7,12 & 4,86 & 6,17 & 4,93 & 6,36 & $p=0,08$ \\
\hline \multirow{2}{*}{ Pré-teste } & $\begin{array}{l}\text { palavras } \\
\text {-iu/-il }\end{array}$ & 3,83 & 5,01 & 4,7 & 3,95 & 3,14 & 4,19 & 4,32 & 3,25 & $p=0,53$ \\
\hline & $\begin{array}{c}\text { pseudopalavras } \\
\text {-il/-iu }\end{array}$ & 2,56 & 3,98 & 3,52 & 3,98 & 2,45 & 3,82 & 3,84 & 2,66 & $p=0,39$ \\
\hline \multirow{2}{*}{$\begin{array}{l}\text { Pós-teste } \\
\text { imediato }\end{array}$} & $\begin{array}{l}\text { palavras } \\
\text {-iu/-il }\end{array}$ & 5,28 & 4,59 & 5,77 & 3,39 & 6,25 & 4,5 & 4,59 & 3,37 & $p=0,46$ \\
\hline & $\begin{array}{c}\text { pseudopalavras } \\
-\mathrm{iu} /-\mathrm{il}\end{array}$ & 2,78 & 3,65 & 4,38 & 2,11 & 6,36 & 4,46 & 4,37 & 3,57 & $p=0,004^{* *}$ \\
\hline \multirow{2}{*}{$\begin{array}{l}\text { Pós-teste } \\
\text { diferido }\end{array}$} & $\begin{array}{c}\text { palavras } \\
\text {-iu/-il }\end{array}$ & 5,11 & 4,57 & 4,8 & 3,04 & 5,71 & 3,46 & 5,02 & 3,21 & $p=0,81$ \\
\hline & $\begin{array}{c}\text { pseudopalavras } \\
\text {-iu/-il }\end{array}$ & 2,56 & 3,37 & 4,59 & 3,57 & 5,61 & 3,98 & 4,48 & 2,38 & $p=0,01 * *$ \\
\hline
\end{tabular}


Além da análise envolvendo o desempenho dos grupos no pós-teste imediato, foi realizada uma ANOVA para analisar as diferenças de desempenho entre os grupos no pós-teste diferido. Por meio dessa prova, pode-se verificar uma diferença significativa entre os grupos na discriminação escrita de palavras ( $F$ $=4,29 ; g l=3 ; p=0,007)$. Porém, em relação à discriminação escrita de pseudopalavras, não se registrou uma diferença significativa no desempenho dos grupos $(F=2,33 ; g l=3 ; p=0,078)$. A comparação do desempenho dos grupos em pares, usando o post hoc (SNK $p<0,05)$, mostra que a diferença entre os grupos deve-se ao desempenho do grupo experimental 2, que é significativamente superior ao dos outros grupos na discriminação escrita de palavras com os elementos mórficos “-am"/“-ão" $(M=8,78)$. Além disso, a comparação entre os pares mostrou que os outros três grupos não diferem entre si em relação à escrita das palavras com esses elementos.

Finalmente, foram realizadas várias ANOVAs para analisar o desempenho dos grupos na escrita de palavras e pseudopalavras com os elementos mórficos "-iu"/“-il". Assim, a análise de desempenho dos grupos no pós-teste imediato mostrou que eles são significativamente diferentes na discriminação escrita de pseudopalavras $(F=4,69 ; g l=3 ; p=0,004)$. No entanto, não se encontraram diferenças significativas entre os grupos na discriminação escrita de palavras ( $F$ $=14,08 ; g l=3 ; p=0,454)$. A comparação do desempenho dos grupos em pares - na discriminação escrita de pseudopalavras -, usando o teste post hoc Least Significant Differences (LSD), mostrou que a escrita dos alunos do grupo 3, que foi objeto desta intervenção específica, foi significativamente superior que a dos alunos dos outros três grupos, cujos desempenhos não diferem entre si.

No que se refere ao desempenho dos grupos na escrita de pseudopalavras e palavras com estes elementos ("-iu"/“-il”) no pós-teste diferido, a análise realizada (ANOVA) mostrou que há diferença significativa entre o desempenho dos participantes na discriminação escrita das pseudopalavras $(F=3,9 ; g l=3 ; p=0,011)$. A mesma análise (ANOVA) mostrou que, de forma semelhante ao que se verificou no pós-teste imediato, não havia diferença significativa entre o desempenho dos grupos no pós-teste diferido em relação à discriminação escrita de palavras com esses elementos $(F=$ $0,33 ; g l=3 ; p=0,810)$.

Entretanto, a comparação dos grupos em pares - na discriminação escrita de pseudopalavras -, feita por meio de testes post hoc Least Significant Differences, mostrou que o desempenho do grupo experimental $3(M=5,61)$ é significativamente superior apenas ao desempenho do grupo $1(M=2,55)$. Em relação aos demais grupos, o desempenho do G3 não é significativamente superior, ou seja, com exceção dos participantes do grupo 1, os participantes dos outros grupos tiveram um desempenho semelhante ao dos alunos pertencentes ao grupo que recebeu instrução explícita sobre esses elementos mórficos.

\section{Discussão}

Existe expressivo suporte teórico e empírico para a afirmação de que nas línguas alfabéticas, tanto a consciência fonológica como a consciência morfológica, exercem papel fundamental na aprendizagem da escrita. Entretanto, muitos estudos que focalizam essas habilidades foram conduzidos em inglês, que é uma língua menos transparente do que o português em termos de correspondência entre letras e sons da fala, o que sugere uma contribuição menos significativa do processamento morfológico na aquisição da linguagem escrita. Pesquisas conduzidas com participantes falantes do Português, variante brasileira, encontraram relações significativas entre o desempenho em provas de consciência morfológica e o desempenho na escrita. Contudo, grande parte dos pesquisadores sugere estudos de intervenção para avaliação do impacto do ensino sistemático de habilidades metamorfológicas sobre a capacidade de escrita.

Assim, este estudo realizou uma intervenção com o objetivo de ensinar diferentes aspectos de morfologia e analisar o impacto dos conhecimentos adquiridos pelos participantes sobre o aperfeiçoamento da escrita.

$\mathrm{Na}$ seção anterior, foram apresentados os dados de desempenho dos participantes na escrita de palavras e pseudopalavras tanto no momento anterior à intervenção (pré-teste) como em dois momentos pós-intervenção (pós-testes imediato e diferido). Os resultados das análises relativas ao desempenho dos participantes na discriminação escrita dos elementos mórficos homófonos "-esa"/“-eza" corroboram os resultados da pesquisa de Pires (2010), os quais demonstraram que, após as intervenções, a média do grupo experimental, independentemente do ano de escolaridade, aumentou, de forma significativa, em relação à média do grupo controle, demonstrando "aprendizagens significativas no grupo experimental e uma certa estagnação no grupo de controle" (Pires, 2010, p. 70). 
Rosa (2003) ressalta a necessidade do desenvolvimento de estudos de intervenção que trabalhem com regras explícitas que regem a discriminação morfológica de morfemas homófonos, "a fim de avaliar se as crianças podem aprender essas regras, e se este aprendizado pode ser mantido em longo prazo" (Rosa, 2003, p. 213). Acredita-se que os resultados obtidos na presente investigação sustentam que é possível a aprendizagem envolvendo regras morfológicas de derivação sobre os elementos mórficos homófonos "-esa"/“-eza”, comprovando pelo pós-teste diferido que tal aprendizado se mantém, mesmo depois de passado um certo tempo.

Destaca-se que, no caso dos elementos mórficos homófonos "-esa"/“-eza", verifica-se que a regra contextual de que o "s" entre vogais tem som de / z/ pode gerar conflito no momento de escrita, tendo em vista que é possível representar o som /z/, presente entre vogais, utilizando tanto a letra "s" quanto a letra " $\mathrm{z}$ " (Rosa, 2003). Diante do conflito da escolha da ortografia correta, quando as crianças não conhecem a regra morfológica, ora recorrem à representação fonológica, ora à regra contextual. No entanto, são capazes de avançar nesse processo quando são ensinadas a respeito, como no treino específico efetivado com os participantes do grupo 1. Dessa forma, embora a morfologia derivacional não tenha sido muito investida no Brasil (Paula, 2007), os resultados deste estudo sugerem que os conteúdos relativos à derivação podem ser explorados em situações de ensino, favorecendo aprendizagens significativas na discriminação escrita de palavras cuja ortografia correta exige conhecimentos específicos.

Em relação ao conteúdo de morfologia flexional trabalhado com o grupo 2, os resultados deste estudo mostram um efeito significativo da intervenção no pós-teste imediato, quer na escrita de palavras, quer de pseudopalavras, mas uma perda de consolidação apenas na escrita de pseudopalavras no pós-teste diferido. A explicação para o que pôde ter ocorrido no pós-teste diferido talvez se deva ao fato de ser ainda possível usar conhecimento lexical para escrever as palavras, mas ser mais difícil mobilizar uma regra morfológica para discriminar tempos verbais em pseudopalavras. Talvez a complementação de treino morfológico com treino fonológico, visto que o elemento mórfico "-am” é um ditongo nasal átono e "-ão" é um ditongo nasal tônico, na sequência dos resultados de Arranhado (2010), possa ser uma boa alternativa para consolidar essas aprendizagens em longo prazo.

Nos pós-testes realizados com o grupo 3, verificou-se que não houve avanço significativo na discriminação escrita de palavras terminadas com os elementos mórficos homófonos "-iu"/“-il". Para tentar compreender o que houve, deve-se considerar que esse treinamento envolviam conhecimentos relativos à flexão verbal, bem como conhecimentos relativos à formação de adjetivos. Ou seja, para se apropriar dos conteúdos trabalhados e utilizá-los na escrita das palavras, os participantes tinham que desconsiderar as "pistas" fonológicas e utilizar conhecimentos morfológicos que englobam flexão e derivação. Acredita-se que os conhecimentos a serem adquiridos nesse caso - discriminação entre os elementos mórficos homófonos "-iu"/“-il" - apresentam uma complexidade maior do que a discriminação dos elementos mórficos trabalhados nas outras situações (“-esa”/“-eza”, “-am”/“-ão”). Talvez esse plano de intervenção, englobando flexão e derivação, possa ser reaplicado em outra pesquisa com estudantes do $5^{\circ}$ ano, visto que o desempenho na escrita de palavras de alguns dos participantes deste estudo (alunos do $4^{\circ}$ ano) aumentou, ainda que não de forma significativa.

Dessa maneira, a partir dos dados obtidos, infere-se que as diferentes regras e conhecimentos relativos à morfologia possam não ser adquiridos no mesmo ano de escolaridade, mesmo que seja feito um ensino explícito desses conteúdos, tendo em vista seu grau de dificuldade. Além disso, um fator que vale ser ressaltado é que, mesmo após a intervenção, alguns dos participantes continuaram a utilizar indiscriminadamente as três possibilidades de registro para /iw/: -iu, -io e -il. Assim, pode-se dizer que as categorias elencadas por Rego e Buarque (2000) foram observadas neste estudo, ou seja, os resultados mostraram que, mesmo após a intervenção, alguns alunos continuaram a escrever como se fala (utilizando "-iu" tanto para verbos quanto para adjetivos), ou optaram pelo uso de uma só representação independentemente do contexto, ou ainda utilizaram a representação "-il" para adjetivos e para alguns verbos, embora também tenha havido situação em que os participantes observaram "plenamente as restrições contextuais” (Rego \& Buarque, 2000, p. 36).

No entanto, é muito relevante ter encontrado um efeito significativo da intervenção na escrita de pseudopalavras quer no pós-teste imediato, quer no pós-teste diferido. Isso sugere que há um efeito do ensino da regra morfológica, quando não é possível acessar a conhecimentos lexicais prévios.

A partir dos resultados obtidos neste estudo, pode-se dizer que, tendo em vista que os grupos eram semelhantes na discriminação escrita dos elementos mórficos ("-esa"/ "-eza"; “-am”/“-ão"; “-iu”/“-il””) 
no início da pesquisa, de uma forma geral, a intervenção possibilitou a aprendizagem dos elementos trabalhados de forma significativa e duradoura, embora constituam exceção a discriminação de pseudopalavras com "-am"/“-ão" e a discriminação de palavras com "-il"/"-iu". Portanto, conclui-se que o ensino explícito de regras morfológicas que favorecem a reflexão sobre esses elementos linguísticos auxilia, significativamente, a escrita de palavras que possuem os elementos trabalhados.

Além disso, no que se refere especificamente à aprendizagem da estrutura morfológica da língua, os resultados aqui apresentados corroboram mais uma vez com Pires (2010), quando afirma que as reflexões sobre a estrutura morfológica das palavras possibilitam aos aprendizes saberes mais produtivos quando se deparam com situações em que sejam necessários tais conhecimentos.

Em suma, os resultados obtidos neste estudo corroboram a defesa de Nunes e Bryant (2006; 2009) quanto à necessidade e importância do ensino explícito sobre morfemas para o aperfeiçoamento da escrita, pois, a partir da compreensão explícita sobre quando utilizar as regras morfológicas trabalhadas, os participantes passaram a dispor de um instrumento cognitivo que lhes possibilitou um aperfeiçoamento ortográfico.

\section{Considerações Finais}

Além das conclusões já explicitadas, a presente investigação possibilitou a verificação de três outros aspectos que merecem ser destacados. O primeiro aspecto diz respeito à constatação, feita no decorrer das intervenções realizadas, de que os participantes não tinham domínio do conteúdo relativo à categoria gramatical das palavras, o que dificultou uma intervenção reportando-se diretamente a substantivos, verbos e adjetivos. Tais saberes eram fundamentais para o aprendizado das regras morfológicas trabalhadas e, apesar do pouco tempo dispensado às intervenções, os participantes conseguiram adquirir conhecimentos expressivos também desse conteúdo.

O segundo está relacionado ao fato de que o presente estudo, embora tenha se constituído de uma investigação de caráter experimental sobre regras morfológicas, indica por meio de seus resultados que o ensino sistemático de tais conteúdos da Língua Portuguesa pode gerar efeitos de aprendizagem explícita, pois permitiu a alocação da atenção, admitindo que o objeto da aprendizagem fosse tomado de modo consciente e deliberado pelo sujeito. (Vidigal de Paula \& Leme, 2010).

Portanto, a partir do que se constatou nesta pesquisa, pode-se pensar em desenvolver estratégias de intervenção pedagógica ou encaminhamentos metodológicos a serem dinamizados pelos próprios professores, em sala de aula regular.

Finalmente, o material elaborado para a intervenção desenvolvida neste estudo pode servir como parâmetro aos professores dos anos iniciais do Ensino Fundamental para a elaboração de seus próprios instrumentos de trabalho pedagógico nessa área. $\mathrm{Na}$ realidade, os resultados aqui evidenciados podem provocar uma pedagogia baseada em evidências científicas, as quais foram testadas, avaliadas e demonstraram bons resultados. Acredita-se que a implementação de atividades de ensino que promovam o desenvolvimento de habilidades metamorfológicas (principalmente relativas à morfologia derivacional, grande ausente nos conteúdos do Ensino Fundamental) poderá impactar positivamente na aprendizagem dos estudantes.

Apesar de oferecer importantes implicações pedagógicas, este estudo, também, demonstra algumas limitações, dentre as quais se pode destacar o período relativamente curto (um mês) decorrido entra a intervenção e o pós-teste diferido. Em estudos futuros, isso poderia ser revisto, ampliando tal intervalo de tempo, de modo a verificar se, de fato, a aprendizagem perduraria.

\section{Referências}

Arranhado, M. (2010). O impacto do ensino de estratégias on morfológicas ou fonológicas na escrita de morfemas homófonos: Estudo de intervenção (Dissertação de Mestrado). Escola Superior de Educação de Lisboa, Lisboa, Portugal.

Byrne, B. (1998). The foundation of literacy: The child's acquisition of the alphabetic principle. UK: Psychology Press.

Camara Jr., J. (2007). Estrutura da lingua portuguesa. 40ª Ed. Petrópolis: Vozes.

Carlisle, J. (1995). Morphological awareness and early reading achievement. In L. B. Feldman (Org.), Morphological aspects of language processing (pp. 189-209). Hillsdale, NJ: Lawrence Erlbaum Associates.

Carlisle, J. (1996). An exploratory study of morphological errors in children`s written stories. Reading and Writing: An Interdisciplinary Journal, 8, 61-72. 
Carlisle, J. (2000). Awareness of the structure and meaning of morphologically complex words: Impact on reading. Reading and Writing: An Interdisciplinary Journal, 12, 169-190.

Cunha, C., \& Cintra, L. (2008). Nova gramática do português contemporâneo. Rio de Janeiro: Lexikon.

Deacon, S., \& Bryant, P. (2005). What young children do and do not know about the spelling of inflections and derivations. Developmental Science, 8, 583-594.

Deacon, S. H., Kirby, J., \& Bell-Casselman, M. (2009). How robust is the contribution of morphological awareness to general spelling outcomes? Reading Psychology, 30, 301-318.

Faraco, C. (2012). Linguagem escrita e alfabetização. São Paulo: Contexto.

Guilford, J. P. (1954). Psychometric methods. McGraw-Hill Book Company, Inc., New York, $2^{a}$ Edição.

Guimarães, S. (2005). Aprendizagem da leitura e da escrita: O papel das habilidades metalinguísticas. $1^{\mathrm{a}} \mathrm{ed}$. São Paulo: Vetor.

Guimarães, S. (2011). Relações entre capacidade de segmentação lexical, consciência morfossintática e desempenho em leitura e escrita. Psicologia: Teoria e Pesquisa, 27(1), 23-32.

Guimarães, S. (2013). O papel da consciência morfossintática na segmentação lexical convencional. Paidéia, 23(55), 225-233.

Guimarães, S. R. K. (2011). Prova de derivação em contexto $e$ de decomposição morfológica. Curitiba. Comunicação pessoal.

Guimarães, S. R. K. (2012). Prova de flexão em contexto. Curitiba. Comunicação pessoal.

Guimarães, S., \& Paula, F. (2010). O papel da consciência morfossintática na aquisição e no aperfeiçoamento da leitura e da escrita. Educar em revista, 38/set.dez., 93-111.

Kehdi, V. (2007). Morfemas do português. $7^{\mathrm{a}}$ ed. São Paulo: Ática.

Marec-Breton, N., \& Gombert, J. (2004). A dimensão morfológica nos principais modelos de aprendizagem da leitura. In M. R. Maluf (Org), Psicologia educacional - questões contemporâneas. São Paulo: Casa do psicólogo.
Moojen, S., Lamprecht, R., Santos, R. M., Freitas, G. M., Brodacz, R., Siqueira, M., Costa, A. C., \& Guarda, E. (2007). CONFIAS - consciência fonológica: Instrumento de avaliação sequencial. Ed. rev. São Paulo: Casa do Psicólogo.

Mota, M. (2007). Complexidade fonológica e reconhecimento da relação morfológica entre as palavras: Um estudo exploratório. Psic, 8(2), 131-138.

Mota, M. (2008). Algumas considerações a respeito do que as crianças sabem a respeito da morfologia derivacional. Interação em Psicologia, 12(1), 115-123.

Mota, M. (2012). Explorando a relação entre consciência morfológica, processamento cognitivo e escrita. Estudos de Psicologia, 29(1), 89-94.

Mota, M., Anibal, L., \& Lima, S. (2008). A morfologia derivacional contribui para a leitura e escrita no português? Psicologia: Reflexão e Crítica, 21(2), 311-318.

Nunes, T. (1992). Leitura e escrita: Processos e desenvolvimento. In E. S. de Alencar (Ed.), Novas contribuições da psicologia aos processos de ensino e aprendiragem. (pp. 13-50). São Paulo: Cortez.

Nunes, T., \& Bryant, P. (2006). Improving literacy by teaching morphemes. London: Routledge.

Nunes, T., \& Bryant, P. (2009). Children's reading and spelling: Beyond the first steps. London: Wiley-Blackwell.

Paula, F. V. (2007). Conhecimento morfológico implícito e explicito na linguagem escrita (Tese de doutorado). Instituto de Psicologia, Universidade de São Paulo, São Paulo e Université de Rennes 2, Rennes, França.

Pinheiro, A. M. V. (1996). Contagem de frequência de ocorrência de palauras expostas a crianças na faixa pré-escolar e séries iniciais do $1^{\circ}$ grau. Belo Horizonte: Associação Brasileira de Dislexia.

Pires, F. (2010). O impacto do ensino de estratégias morfológicas no desenvolvimento da escrita: Um estudo de intervenção. (Dissertação de Mestrado). Escola Superior de Educação de Lisboa, Lisboa, Portugal.

Queiroga, B., Lins, M., \& Pereira, M. (2006). Conhecimento morfossintático e ortografia em crianças do ensino fundamental. Psicologia: Teoria e Pesquisa, 22, 95-100.

Rego, L., \& Buarque, L. (2000). Algumas fontes de dificuldade na aprendizagem de regras ortográficas. In 
A. G. Morais. O aprendizado da ortografia. $2^{\mathrm{a}}$ Ed. Belo Horizonte: Autêntica.

Rocha, L. C. A. (1998). Estruturas morfológicas do português. Belo Horizonte: UFMG.

Rosa, J. (2003). Morphological awareness and spelling development (Doctoral thesis). Department of Psychology, University of Oxford Brookes, Oxford, London, England.

Seabra, A., Montiel, J., \& Capovilla, F. (2009). Prova de aritmética. In A. G. Seabra \& F. C. Capovilla. Avaliação neuropsicológica. $2^{\mathrm{a}} \mathrm{Ed}$. São Paulo: Memnon.
Silva, M., \& Koch, I. (1997). Linguística aplicada ao português: Morfologia. São Paulo: Cortez.

Vidigal de Paula, F., \& Leme, M. I. S. (2010). Aprendizagem implícita e explícita: Uma visão integradora. Psicologia em pesquisa (UFJF), 4, 15-23.

Recebido: 22/04/2014 $1^{a}$ reformulação: 21/12/2014

Aprovado: 06/01/2015

Sobre os autores:

Viviane do Rocio Barbosa é graduada em Pedagogia pela Universidade Federal do Paraná, mestre e doutora em Educação pela Universidade Federal do Paraná, professora substituta na Universidade Federal do Paraná e pedagoga da rede municipal de ensino de Curitiba.

Sandra Regina Kirchner Guimarães é graduada em Psicologia pela PUCPR, mestre em Educação pela Universidade Federal do Paraná, doutora em Psicologia Escolar e do Desenvolvimento Humano pela Universidade de São Paulo e professora permanente do Programa de Pós-graduação em Educação da Universidade Federal do Paraná.

João Manuel dos Santos Rosa é graduado em Psicologia pelo Instituto Superior de Psicologia Aplicada de Lisboa, ph.D. em Educação (com foco em Psicologia) pela Oxford Brookes University, professor sênior da Escola Superior de Educação de Lisboa e da Universidade Autônoma de Lisboa.

Contato com os autores:

Universidade Federal do Paraná - Curitiba

Rua Emílio Scuissiato, 127, Fazendinha, Curitiba - Paraná

CEP: 81.330-270.

E-mail: vivipedago@gmail.com 